\title{
Review
}

\section{Strategies and Challenges in the Development of Coronavirus Disease-2019 Vaccine}

\author{
Pratibha Gupta, MSc, PhD* \\ Department of Biotechnology, Radha Govind University, Ramgarh 829/22, Jharkhand, India
}

"Corresponding author

Pratibha Gupta, MSc, PhD

Assistant Professor, Department of Biotechnology, Radha Govind University, Ramgarh -829|22, Jharkhand, India; Tel. +9l 9304878508;

E-mail: pratibhagupta2007@gmail.com

\section{Article information}

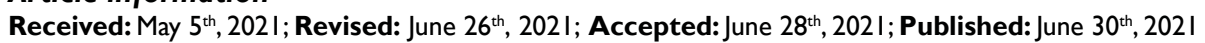

\section{Cite this article}

Gupta P. Strategies and challenges in the development of coronavirus disease-20I9 vaccine. Epidemiol Open J. 202I; 6(I): I- I0. doi: I0. I7| 40/EPOJ-6-I22

\begin{abstract}
The novel coronavirus infection (coronavirus disease-2019 (COVID-19)) emerged from Wuhan in the Hubei Province of China in late 2019. Millions of people were infected with COVID-19 pandemic due to the long incubation period of the virus inside the human body and the dearth of available treatments or vaccines. High transmission rates created havoc, which highlighted the urgent need for effective interventions to stop the spread and clinical impact of the virus on patients and populations. Previous research on severe acute respiratory syndrome coronavirus (SARS-CoV) provides information on vaccination strategies that could inform how governments approach the elimination of this novel coronavirus. Numerous efforts have been made to develop vaccines against Middle East respiratory syndrome (MERS) and SARS. The spike glycoprotein or S protein is the critical target for most of the drugs and vaccines against coronavirus. The virus uses the spike (S) protein for entering the host cell, by interacting with the receptor called angiotensin converting enzyme-2 (ACE2). Various vaccine platforms are available such as nucleic acid vaccine, protein-based vaccines, virus-vectored vaccines and live or attenuated vaccines, with each having their advantages and disadvantages. This review focuses on the overview of different vaccine candidates used, those currently in development, and the challenges encountered while developing effective vaccines.
\end{abstract}

\section{Keywords}

SARS-CoV-2; Vaccine development; Clinical trials.

\section{INTRODUCTION}

$\mathrm{T}$ he outbreak of coronavirus disease-2019 (COVID-19) was first reported in Wuhan, Hubei Province of China in late 2019. The disease was caused by severe acute respiratory syndrome coronavirus-2 (SARS-CoV-2), which spread to almost all parts of the globe. The symptoms include fever, cough, chest tightness, and fatigue upon exertion. Most patients experience mild symptoms whereas some are asymptomatic (have no clear or confirmed symptoms). ${ }^{1,2}$ Long incubation, high infection rates and mild to moderate symptoms make COVID-19 a troubling disease. The World Health Organization (WHO) declared this outbreak a pandemic on 30 January 2020. Physical distancing and other transmission mitigation strategies were implemented in most countries to prevent citizens from being infected. The SARS-CoV-1 outbreak in 2003 caused similar respiratory symptoms and amassed 774 deaths. Middle Eastern respiratory syndrome coronavirus (MERS-CoV) often involves similar symptomatology and infections in Saudi Arabia in
2012 were circulated between bats and camels before transmission to humans ("zoonotic" transmission). ${ }^{3}$

The coronavirus is an enveloped and positive sense single stranded ribonucleic acid (RNA) genome. It belongs to the Betacoronavirus genus containing $30 \mathrm{~kb}$ genome with 14 open reading frames (ORF). The ORFs includes four viral structural proteins: Membrane (M), Spike (S), Nucleocapsid (N) and Envelope (E) protein. ${ }^{4-7}$ The $\mathrm{S}$ protein is functionally composed of two subunits, S1 (receptor binding) and S2 (cell membrane fusion). ${ }^{8,9}$ During infections, host cell proteases process the $\mathrm{S}$ protein at the S1/S2 cleavage site. Proteolytically processed $\mathrm{S}$ protein cleaves into two subunits, the $\mathrm{N}$-terminal at the $\mathrm{S} 1$ subunit and the $\mathrm{C}$-terminal of the S2 subunit. The S1 subunit consists of N-terminal, signal peptide, and receptor binding domains. The $\mathrm{S} 2$ subunit consists of a C-terminal domain, conserved peptide sequences, proteolytic sites, a transmembrane domain and a cytoplasmic domain. ${ }^{10-12}$ As the virus enters the host cell, another cleavage occurs for the fusion of 
membranes and the cleavage is mediated by endolysosomal proteases. ${ }^{8}$ Furin is highly expressed in lungs and the $\mathrm{S}$ protein contains the potential cleavage site for furin protease. Furin like cleavage appears to be the important for the activation of $\mathrm{S}$ protein which leads to the efficient entry of the virus into the host cell. ${ }^{13}$

Coronavirus (CoVs) can infect a range of host species such as animals, birds and humans. Different CoVs like SARSCoV, MERS-CoV and SARS-CoV-2 have intricate host receptor recognition patterns, which indicate the structural diversity in the receptor binding domain of the $S$ protein. The interaction between the S-protein and the angiotensin-converting enzyme 2 (ACE-2) receptor present on the host cell is the probable mechanism of the infection that is caused by SARS-CoV- $2 .{ }^{14}$

According to WHO guidelines, the COVID-19 infected patients should receive supportive body system-focused therapies like fluid therapy, oxygen therapy and antibiotics. The major therapeutics drugs include lopinavir, ritonavir, remdesivir along with interferons, monoclonal antibodies and convalescent plasma for the treatment. ${ }^{15}$ Remdesivir was originally developed for the treatment of Ebola virus infection. It prevents the viral infection by premature termination of RNA transcription. ${ }^{16}$ Remdesivir is a nucleoside analogue drug which is in Phase III of clinical investigation against COVID-19 (NCT04292730, NCT04315948, NCT04257656). An open-label, randomized Phase II clinical trial found that triple antiviral therapy (lopinavir, ritonavir and interferon beta-1b) was safe in alleviating symptoms and shortening the duration of viral shedding. There is an unprecedented need to develop and distribute safe and effective vaccine to protect the entire global community from continued mortality from COVID-19 should be intact. The wide geographic diversity of the pandemic requires an effective vaccine approach, for this the collaboration between biotechnologist and pharmaceutical companies is needed which brings the convergence of a variety of vaccine development approaches. Over the past decade, the vaccine industry and scientific community responded urgently to several epidemics such as H1N1 influenza, Ebola, Nipah virus as well as against CoVs including MERS- and SARS-CoVs. ${ }^{17-19}$ Developing vaccine against $\mathrm{H} 1 \mathrm{~N} 1$ influenza is relatively rapid as influenza vaccine technology is well-established and key regulators were already decided. Many efforts have been directed to develop vaccine against CoVs infection but the limiting factor is most often the degree of crossreactivity. ${ }^{20}$ Immune response by the body against SARS-CoV-2 vaccine plays a vital role for preventing the pathogen's entry into human cells. However, an unregulated immune response may lead to immunopathogenesis.

There is a challenge in developing safe and effective vaccines, but manufacturing, distributing and administering it to the population within a short time frame is an extraordinary challenge. Approximately, 321 COVID-19 vaccine candidates are available, out of these 66 vaccines are in activeclinical trials (Table 1 ) and 176 are in the pre-clinical (animal) phase of testing. ${ }^{21}$

An ideal vaccine should be safe even to immunocompromised people, inexpensive, free from toxicity, have high thermal stability and should confer long-term protection. ${ }^{22}$ Various scien- tific communities are using multiple approaches to shorten the development phase which include efficiency gains via over-laying on one other of the traditional, sequential clinical "phases" of progressive testing prior to approval. This, while accomplishing research objectives more quickly than is usual, must be carefully monitored for rigor and reliability of conclusions reached at such previously-unexpected speeds. In addition to the more usual scientifically cautious approach to study and conclusion-drawing, these diverse types of vaccine candidates face a variety of challenges that are related to development, manufacturing, storage, and distribution, to mass vaccination.

\section{VACCINE DESIGN STRATEGIES}

The SARS-CoV-2 pandemic created a devastating situation across the globe. ${ }^{14}$ Children and adults above 65 -years of age are more vulnerable to COVID-19. Vaccination enable the natural viral infection defense system, which is the only way to control the COVID-19 outbreak. Vaccine design includes the selection of a target antigen key in the virus' infection process, a "vehicle" (viral, genetic/recombinant, chemical, etc.) for vaccine delivery into patients, and the intended or optimal vaccination administration route (oral, nasal, injection, etc.). The selection of a target antigen is based upon the structural and pathobiology information of SARS-CoV-2. The genome of SARS-CoV-2 is a single stranded positive sense RNA. The positive sense genome can act as messenger RNA that can be directly translated into viral protein by the host cell ribosome. The structural proteins present in the virus include Nucleocapsid (N) protein, spike $(\mathrm{S})$ protein, membrane $(\mathrm{M})$ protein and envelop $(\mathrm{E})$ protein. $\mathrm{N}$ protein coats the positive stranded RNA genome which is enclosed in a lipid envelop into which $\mathrm{S}, \mathrm{M}$ and $\mathrm{E}$ protein are inserted. The $\mathrm{S}$ protein located at the outer surface of virus binds with an ACE-2 receptor on the host cell surface, allowing receptor mediated endocytosis of the virus (Figure 1$).{ }^{23} \mathrm{~S}$ protein plays an important role in the virus life cycle that enables it to enter human cells, so the spike protein is a rational priority prime target for most of the COVID-19 vaccines. Based on crystallography ACE2 binding patterns in SARS-CoV and SARS-CoV-2 are the same. ${ }^{24}$ Previously, while developing vaccine against SARS-CoV, liver damage was observed when a full-length $\mathrm{S}$ protein was used as a vaccine antigen. ${ }^{25}$ Thus, the fragment of S-protein, the receptor binding domain (RBD), was seen as a safer choice as a vaccine candidate for COVID-19. However, RBD-based vaccines face problems arising from low immunogenicity, identifying possible appropriate adjuvant(s), establishing an immunization schedule, and partial versus full fragment length approaches. ${ }^{26}$ Vaccine candidates in development have several advantage and disadvantages. The most important features that should be considered to develop vaccine candidate are antigen-specific cellular immunity, long-term protection and the ability to induce a reliable and sufficient systemic immune system response. ${ }^{27,28}$ Vaccine candidates for COVID-19 were classified into vector-based vaccines, recombinant protein-based vaccines, deoxyribonucleic acid (DNA) vaccines, messenger RNA (mRNA) vaccines, recombinant protein vaccines, inactivated vaccines, live attenuated vaccines and viral vector-based vaccines.

\section{Deoxyribonucleic Acid Based Vaccine}

Deoxyribonucleic acid vaccines are encoded with an antigen-pre- 


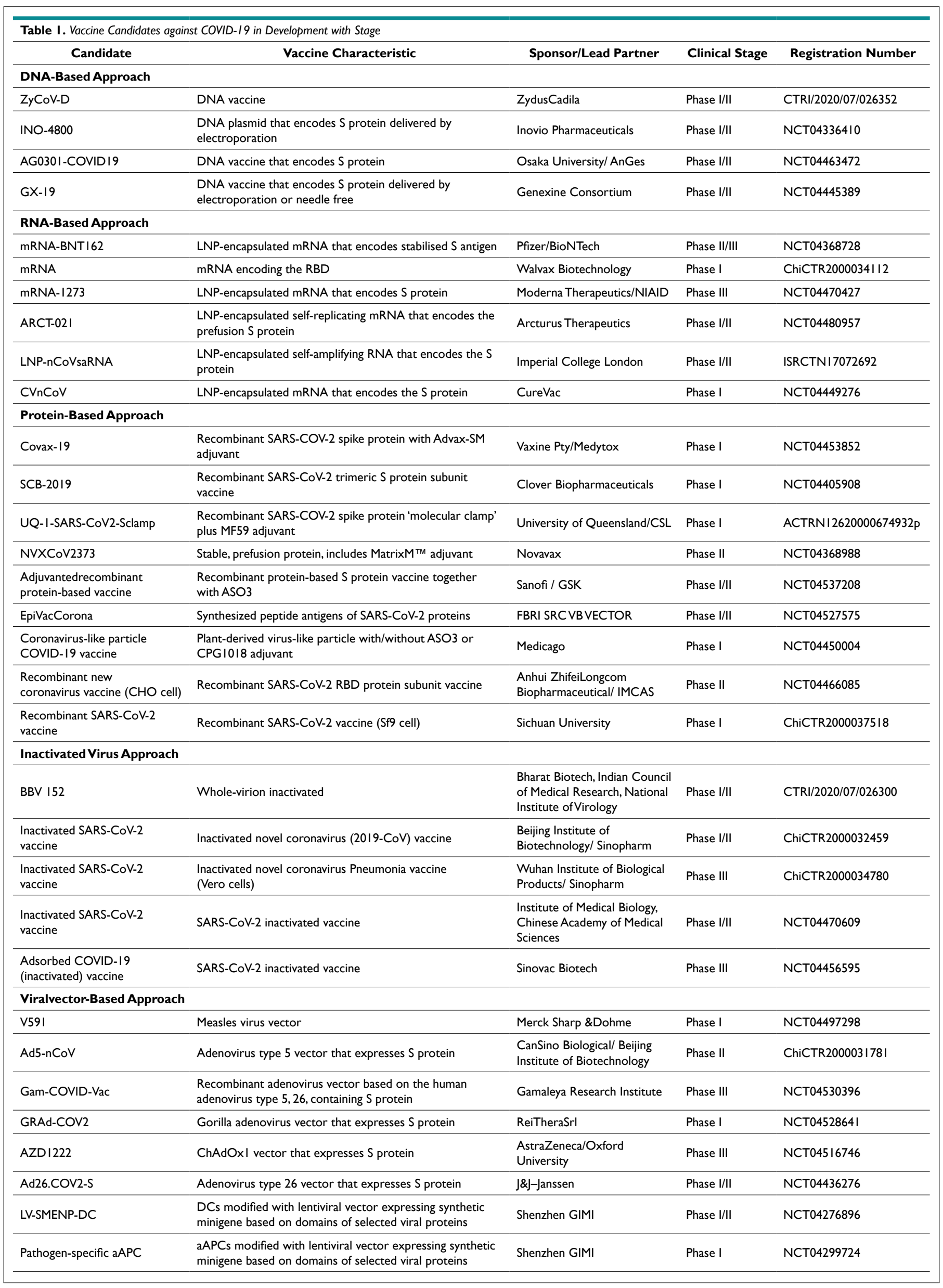



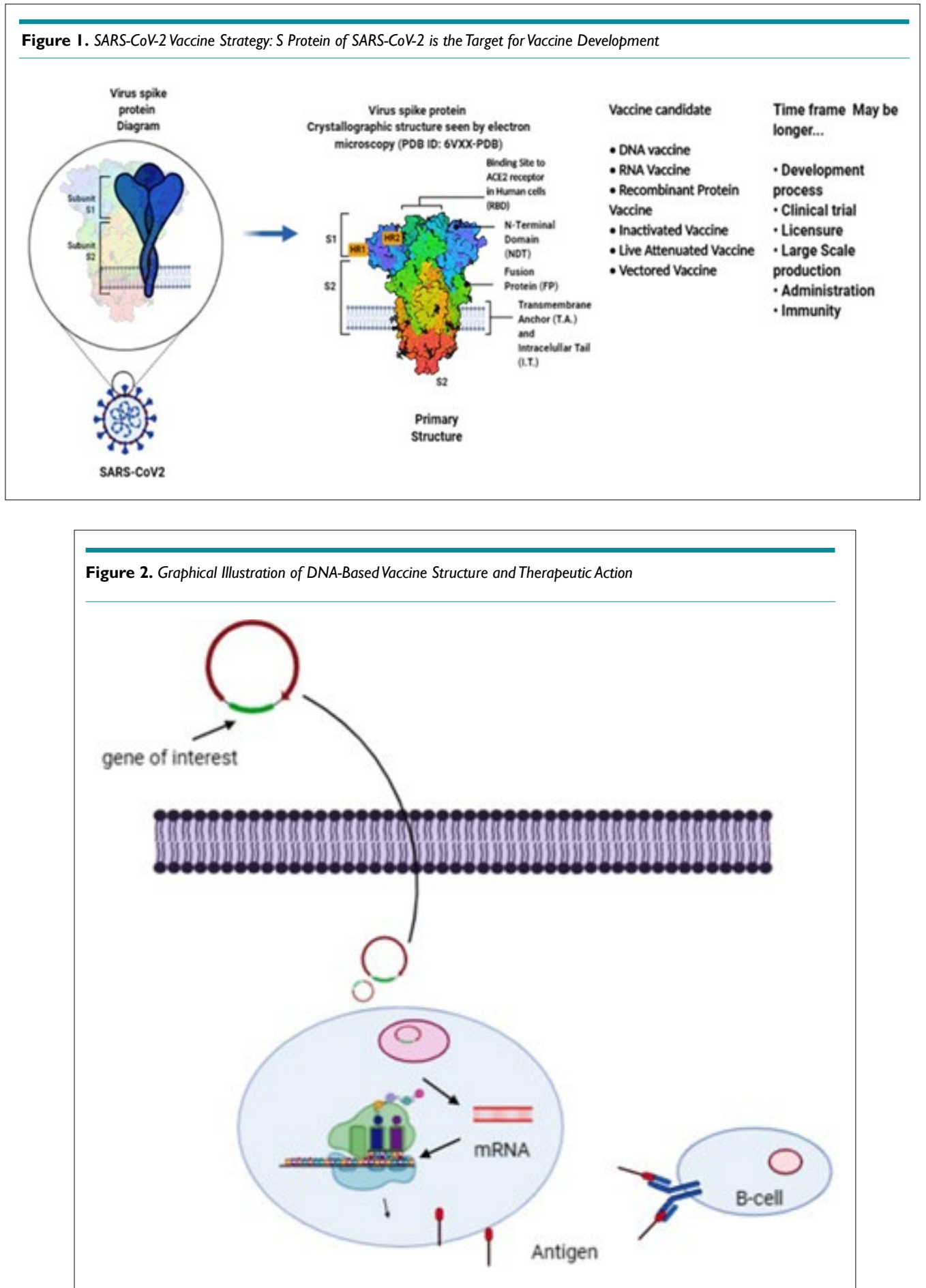

senting cell which is intended to elicit humoral immune response that is like that of an atural infection. ${ }^{29}$ The antigen-encoding DNA is enclosed with lipid nanoparticles can be delivered into the cytoplasm of the host cell and further it is processed into antigen peptide that elicits $\mathrm{CD}^{+}{ }^{+}$T-cell response. ${ }^{30}$ DNA plasmids cross the plasma and nuclear membrane, enter the target cell, reach the nucleus and achieve transcription and thus propagates the desired and validated immune response (Figure 2). DNA vaccines have various advantages such as eliminating the use of live viruses, ease of production scaling, lower production costs when compared to protein vaccine production, more stability for storage and trans- portation and they may even be administered to immuno-compromised patients. Manufacturing DNA based vaccines is relatively straight forward and is more stable than viral protein and RNA vaccines. The only pro-inhibitory factor is the low immunogenicity that sometimes requires multiple booster doses. ${ }^{31,32}$ Overcoming the immunogenic issues of DNA vaccines, immunostimulants and adjuvants maybe required. Combined use of granulocyte-macrophage colony-stimulating factor (GM-CSF) and a cytokine-based therapy directed against interleukin-4 (IL-4) have proven useful in enhancing immune response in some medical settings. ${ }^{33}$ DNA vaccines show promising effects against several emerging viral dis- 
eases such as Dengue, MERS, and Chikungunya. ${ }^{34-36}$ Yet, no DNA vaccine has been licensed for use in human. DNA-based vaccines encoding $\mathrm{S}$ protein from SARS-CoV-2 appears to be in clinical Phase I/II testing on the pathway to approval. ${ }^{37}$

\section{Ribonucleic Acid Based Vaccines}

Messenger RNA (mRNA) sequences that code for disease specific antigens enclosed with lipid nanoparticles (LNPs) are the current, most widely pursued mechanism of action for approved COVID-19 vaccines. ${ }^{38}$ Once the LNP is phagocytosed (eaten/incorporated) by the human cell, the RNA condensing lipid nanoparticle punctures the endosome and allows the mRNA molecule to release into the cytosolinside the human cell (Figure 3). Messenger RNA vaccines are synthesized by in vitro transcription and are noninfectious. This feature of mRNA vaccines does provide advantages that differentiate it from recombinant viral vector vaccines, live attenuated viral vaccines and inactivated viral vaccines that enable inexpensive and rapid production of vaccine doses. ${ }^{39}$ The mRNA vaccine does not integrate permanently into the human host genome and does not produce any live infectious particles that elicit immune responses and this further reduces safety concerns.

Moderna's COVID-19 vaccine candidate mRNA-1273, encodes SARS-CoV-2 S protein encapsulated in lipid nanoparticles, and is in Phase III clinical trials.

\section{Protein Vaccines}

Protein vaccines contain partial or full-length SARS-CoV-2 S pro- tein that induces a $\mathrm{CD}^{+}{ }^{+} \mathrm{TH}$-cell and antibody response. Unlike nucleic acid-based vaccine, protein subunit vaccines could have improper epitope conformation, until they are produced by mammalian cells. ${ }^{40}$ Protein vaccines are designed to provoke the immune response towards neutralizing epitopes, thus preventing the production of non-neutralizing antibodies that may promote antibody- dependent enhancement (ADE) of disease. ${ }^{41}$ Protein subunits (when used alone) are poorly immunogenic and thus serve as poor activators of the $\mathrm{CD} 8^{+} \mathrm{T}$-cell response, which requires adjuvant and repeated administrations. Recombinant proteins are enclosed in a virus like particles (VLPs) devoid of viral genome. The VLPs generate high numbers of antigenic epitope copies, thereby preserving viral immunogenicity, enabling the ability to crosslink to B-cell receptors on the B-cell surface and facilitate uptake by the antigen presenting cells (APCs) (Figure 4). ${ }^{42,43}$ In protein-based vaccines, subunits are taken up by the antigen presenting cells for $\mathrm{B}$-cell recognition through $\mathrm{B}$ cell receptor (BCR) and for major histocompatibility complex (MHC) presentation. In viral-vector vaccines, (replicating and non-replicating) viral vectors or cellular vehicles, carrying a desired gene, are delivered and facilitate the expression of heterologous antigen within the cell. The viral vector retains the capacity to produce viral particles that infect the host cell and that lead to transgene expression and antigen presentation. Live virus vaccines retain the ability to replicate inside the host cell and mimic the natural infectionprocess. The inactivated virus vaccines deploy virus cells that were once alive and have been completely attenuated, yet still generate an infectious state. They do so by using certain chemicals that induce specific neutralizing antibodies in response to what the viral vaccine presents to the human body.

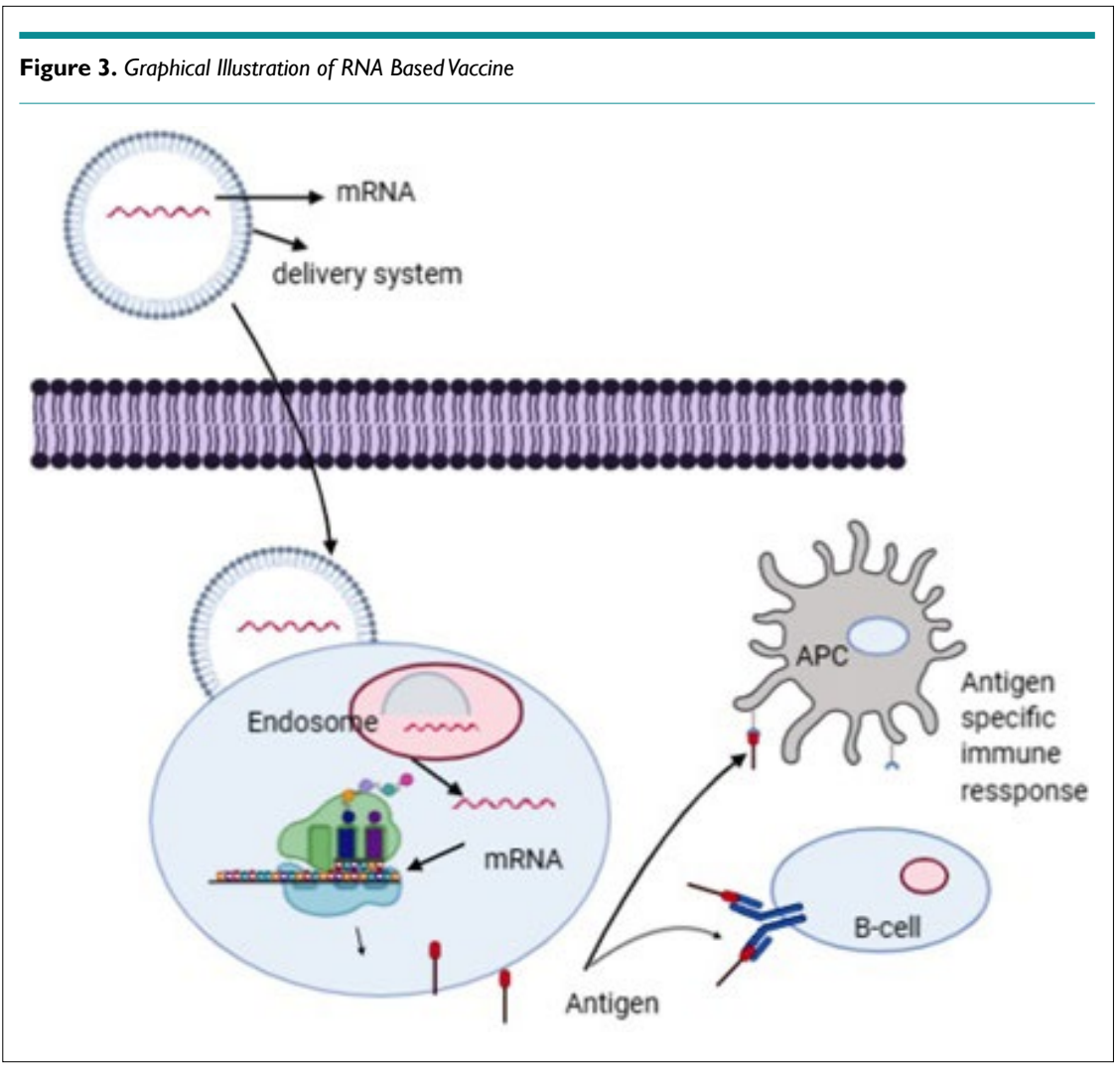


Figure 4. Graphical Representation for Vaccine Design Strategies: Protein Based Vaccines-Subunits are Taken-up by the Antigen Presenting Cells for B-Cell Recognition through BCR and for MHC Presentation

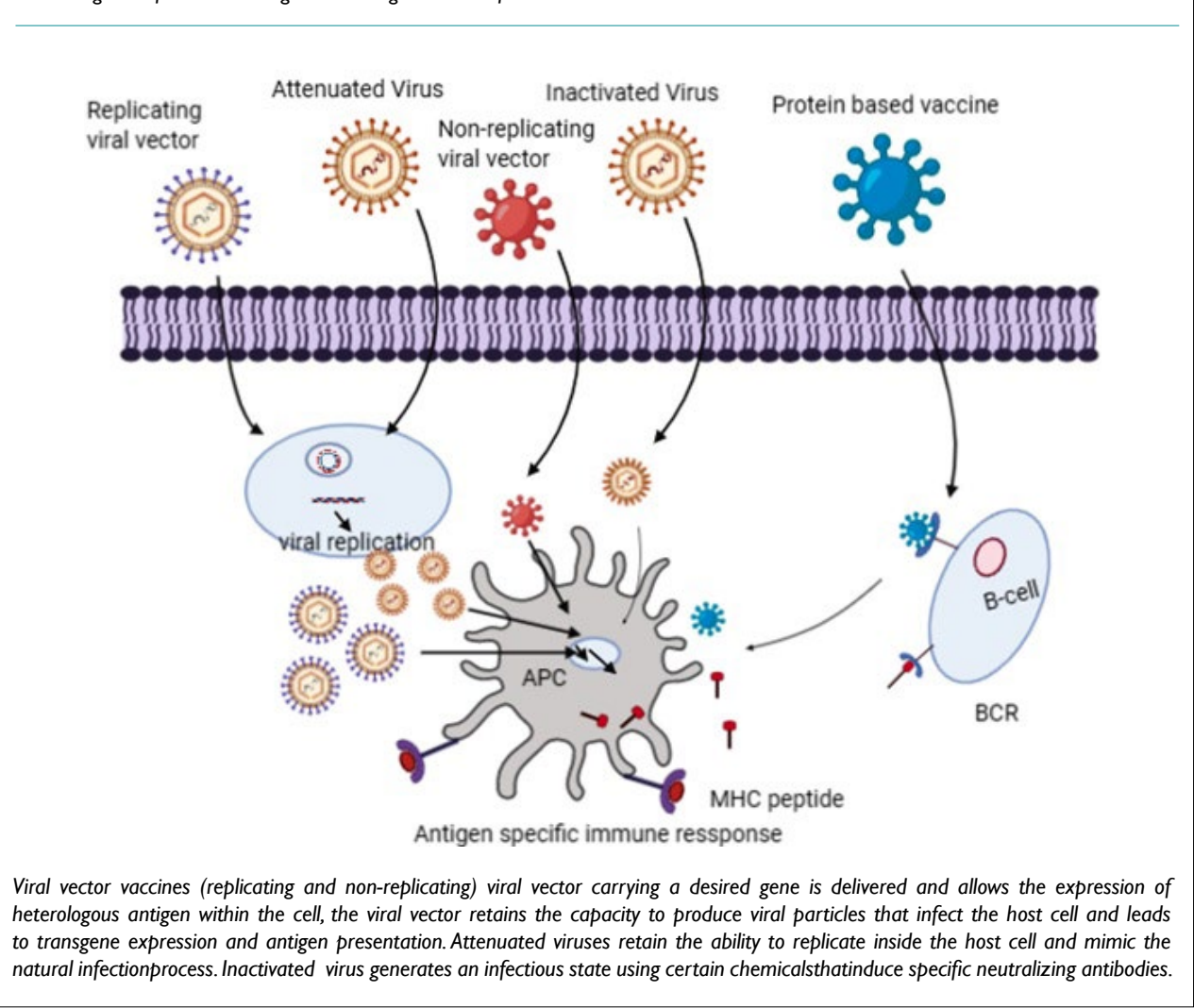

\section{Attenuated and Inactivated Virus Vaccine}

The attenuated vaccines are obtained by mutating a virus, which infects the human cell until a substantial number of cells adopt the mutation that generates the desired immune response (Figure 4). Their most important advantage is that they offer more than one antigenic component to host, thus inducing or mobilizing various immunological effectors against the virus. ${ }^{44}$ The drawback associated with attenuated vaccines are potential safety concerns. They often have high reactogenicity compared to protein-based vaccines. ${ }^{45}$ Several successful vaccines such as bacillus-calmette-guerin (BCG) and measles vaccines are based on attenuated strains of the viruses. ${ }^{46}$ The coronavirus genome has various genes that are not required for replication and can be deleted. Deletion of various genes that code for non-structural proteins and structural $\mathrm{E}$ proteins may also be used as a strategy to design new vaccines. ${ }^{45,47,48}$ Therefore, deletion of the virulence factor and the induced codon deoptimization (where nucleic acid sequence is modified that encodes the wild type of amino acid sequence, and slows the translation of viral protein) may be a suitable mechanism of attenuation. A codon deoptimization approach yields vaccine-ready virus that is highly attenuated in vivo and in vitro and can replicate if the correct viral protein(s) is/are selected forde-optimization. . $^{49,50}$

In inactivated vaccines, the whole pathogen is killed either by exposure to chemical (formaldehyde) or heat induced inactivation. ${ }^{51}$ Inactivated viruses have been used traditionally for vaccine development and were found to be safe and effective for prevention of diseases caused by the hepatitis influenza, and polioviruses.
They are generally less immunogenic and require multiple doses or an additional adjuvant (Figure 4). ${ }^{52,53}$ Currently there are five vaccine candidates for SARS-CoV-2 (Table 1) apart from that there are nine inactivated vaccine that is in preclinical stage (WHO). Inactivated vaccine candidate (NCT04456595) developed by Sinovac Biotech Ltd in China, is currently in phase III clinical trials. ${ }^{54}$

\section{Viral Vector Based Vaccines}

Viral vector-based vaccines use either replicating or non-replicating viruses (Figure 4) to induce the human immune response. It represent the biotechnological evolution of inactivated and attenuated vaccines, which are viral backbones devoid of replication machinery and used as a vehicle to deliver in vivo and express antigens derived from target pathogens. The viral- based vaccine has ability to induce strong T-cell responses without the need forany adjuvants. ${ }^{55,56}$ One of the drawbacks of viral vector vaccines is that it requires multiple immunizations to achieve the level of immunogenicity and thus protection against the virus but may also lead to ahost response against the structural viral protein, thus limiting the efficacy of immunization (called a neutralizing antibody). ${ }^{55}$ This limitation is overcome by using aheterologous prime boost regimen that is introduced in several clinical trials. ${ }^{57}$

Heterologous prime-boost vaccine regimens means to deliver the same or similar antigens through different vaccine types, the first to prime and the second to boost the immune system.

Currently there are eight viral-based vaccine candidates 
is in clinical trials (Table 1). Ad5- $\mathrm{nCoV}$ (NCT04341389) is a viral vector-based vaccine candidate that has been in Phase III of clinical trials. The replicating viral vaccine candidates are based ona vaccine strain derived from the human pathogen. It is important to consider this very specifically, if the potential recipient of the vaccine has pre-existing exposure and presumed subsequent immunity against the virus. Pre-existing antibodies can impair the ability of vaccine to elicit the immune response required for protection. Non-replication viral vector vaccine candidates are mostly based on adenovirus (Ad5) and express the $\mathrm{S}$ protein or receptor binding domain (RBD) of SARS-CoV-2.

\section{Safety Measures for Coronavirus Disease-2019 Vaccines}

COVID-19 cases do not seem to be declining and the ebb and flow of cases are mostly driven by human attitude towards physical distancing and protective measures. All eyes remain on pharmaceutical companies and research institute involved in vaccine development. Traditionally new vaccine development and approval requires 10-12-years, and there are enormous pressures and challenges to minimize that time frame. The safety of a vaccine is generally determined by the choice of adjuvant, nature of vaccine platform, mode and route of vaccine administration, status of pre-existing vaccine immunity and age of vaccines. In the particular case of SARS-CoV-2, the individual is either symptomatic or asymptomatic, and COVID-19 vaccines are developed with a goal of mass immunization or protection and not addressing symptomatology. Any loophole in the lack of safety considerations may support the mobilization of anti-vaccination movements or messaging, which would jeopardize the effect of achieving mass immunization.

As other respiratory viral infections, vaccine strategies for COVID-19 require additional safety vigilance. There is a possibility of antibody-dependent enhancement (ADE) of disease if an insufficient immune response is mounted in a situation of the unresolving, active, and serious disease. Over production of proinflammatory cytokines in lung immunopathology that cause additional damage when vaccines cannot stop SARS-CoV-2 pathology early in the process. In this regard, COVID-19 vaccine trials were initially conducted in healthy adults with age of 55-years or younger and later stage trial includes seniors. ${ }^{58,59}$

\section{DISCUSSION}

The COVID-19 pandemic emerged as wide spread SARS-CoV-2 infection in December 2019, according to most estimates. Several challenges exist in the development of vaccines against COVID-19 as the novel SARS-CoV-2 is undergoing several genomic changes, even as of the time of this writing. Developed vaccine candidates include approaches with inactivated viruses, live attenuated viruses, virus nucleic acid-based vaccine, and protein subunit vaccines. All are in different clinical phases. Moderna's vaccine; the inactivated virus vaccine being developed by Sinopharm, the Wuhan institute of Biological products; and Sinovac Biotech are on the market as of this writing. According to WHO Global Advisory Committee, AstraZeneca (adenovirus vector vaccine) is that, it is safe and effective for protecting people from the serious risk of COVID-19. The ideal vaccine candidate for COVID-19 should be safe, effective and have a good immunogenicity profile among all age groups and be safe for including pregnant women and immuno compromised individuals. For ease of success, the effective vaccine should generate humoral and cellular immunity with a single dose of vaccination. Generating effective vaccines has required initiating a large number of official projects by the WHO, various companies, universities and laboratories. Approval of the first COVID-19 vaccine in increased the enthusiasm and possibilities for developing second and third generation vaccine approaches and candidates for approval. ${ }^{60,61}$ COVID-19 eradication programme is time taking after vaccination, as the various mutant strains are available now e.g. South Africa variant (501Y.V2), which show different symptoms in infected humans than previous strains.

\section{CONCLUSION AND FUTURE GUIDEANCE}

Various companies and institutes are in the position to offer several treatment strategies against the COVID-19 pandemic. Tireless and ongoing scientific efforts have led to the development of 242 COVID-19 vaccines candidates. We are in the early stage of SARS$\mathrm{CoV}-2$ identification and adequate vaccine preparation, manufacturing, and distribution to populations. Based on previous studies, it may be inferred that the COVID-19 vaccines approved thus far provide acceptable (if not higher than previously experienced) immunity and protection via a durable neutralizing antibody and a lasting T-cell response.

Various vaccine strategies are being pursued now with attendant advantages and disadvantages. According to the WHO, the vaccine must be of high efficacy and producing only mild or transient adverse effects an acceptable and benefit-risk contour. Various vaccine platforms depend upon adjuvants for inducing the T-cell response. Live attenuated vaccines are not recommended, as a delivery vector increases the risk of pathogen conversion to actual viral infection. Viral vectored vaccines are effective in inducing T-cell response but sometimes their efficiency is affected by cross-reactive immunity (antibodies that neutralize the antibodies mobilized by the vaccine). Nucleic acid based vaccines are also a successful candidate but they need specific delivery vehicles or adjuvants. In many countries, emergence of new cases and transmission of COVID-19 diseases is significantly declining whereas in some countries the number of new cases increase day-by-day. Approved vaccines must be suitable for persons of all ages, pregnant mother, lactating mother as well as immunocompromised person. To meet the need or demand of less wealthy countries, the funding committed through the COVAX program (COVID-19 Vaccine Global Access) and coalition for epidemic preparedness innovation (CEPI) unite rich and low- income countries to achieve rapid and fair access to the most effective COVID-19 vaccines. Since vaccines alone cannot combat the pandemic and assure its elimination, prevention strategies and social strategies will remain needed and such strategies will also help us to face future pandemics.

\section{REFERENCES}

1. Lake MA. What we know so far: COVID-19 current clinical knowledge and research. Clin Med (London). 2020; 20: 124-127. doi: 10.7861/clinmed.2019-coron 
2. Guan WJ, Ni ZY, Hu Y, Liang WH, Ou CQ, He JX, et al. Clinical characteristics of coronavirus disease 2019 in China. N EngJ Med. 2020; 382: 1708-1720. doi: 10.1056/NEJMoa2002032

3. Azhar EI, El-Kafrawy SA, Farraj SA, Hassan AM, Al-Saeed MS, Hashem AM, et al. Evidence for camel-to-human transmission of MERS coronavirus. N Eng J Med. 2014; 370: 2499-2505. doi: 10.1056/NEJMoa1401505

4. Lu R, Zhao X, Li J, Niu P, Yang B, Wu H, et al. Genomic characterisation and epidemiology of 2019 novel coronavirus: Implications for virus origins and receptor binding. Lancet. 2020; 395: 565-574. doi: 10.1016/S0140-6736(20)30251-8

5. Wu F, Zhao S, Yu B, Chen YM, Wang W, Song ZG, et al. A new coronavirus associated with human respiratory disease in China. Nature. 2020; 579: 265-269. doi: 10.1038/s41586-020-2008-3

6. Zhou P, Yang XL, Wang XG, Hu B, Zhang L, Zhang W, et al. A pneumonia outbreak associated with a new coronavirus of probable bat origin. Nature. 2020; 579: 270-273. doi: 10.1038/s41586020-2012-7

7. Wan Y, Shang J, Graham R, Baric RS, Li F. Receptor recognition by the novel coronavirus from Wuhan: An analysis based on decade - long structural studies of SARS coronavirus. J Virol. 2020; 94: e00127-20. doi: 10.1128/JVI.00127-20

8. Le TT, Andreadakis Z, Kumar A, Roman RG, Tollefsen S, Saville $\mathrm{M}$, et al. The COVID-19 vaccine development landscape. Nat Rev Drug Discov. 2020; 19: 305-306. doi: 10.1038/d41573-020-00073-5

9. He Y, Zhou Y, Liu S, Kou Z, Li W, Farzan M, et al. Receptorbinding domain of SARS-CoV spike protein induces highly potent neutralizing antibodies: Implication for developing subunit vaccine. Biochem Biophys Res Commun. 2004; 324: 773-781. doi: 10.1016/j.bbrc.2004.09.106

10. Le Coupanec A, Desforges M, Meessen-Pinard M, Dube M, Day R, Seidah NG, et al. Cleavage of a neuroinvasive human respiratory virus spike glycoprotein by proproteinconvertases modulates neurovirulence and virus spread within the central nervous system. PLoS Pathogens. 2015; 6: 11,e1005261. doi: 10.1371/journal. ppat. 1005261

11. Kirchdoerfer RN, Cottrell CA, Wang N, Pallesen J, Yassine HM, Turner HL, et al. Pre-fusion structure of a human coronavirus spike protein. Nature. 2016; 531: 118-121. doi: 10.1038/nature17200

12. Walls AC, Tortorici MA, Snijder J, Xiong X, Bosch BJ, Rey FA. et al., Tectonic conformational changes of a coronavirus spike glycoprotein promote membrane fusion. Proceedings of the National Academy Sciences of the United States of America. 2017; 114: 1115711162.

13. Bassi DE, Zhang J, Renner C, Klein-Szanto AJ. Targeting proproteinconvertases in furin-rich lung cancer cells results in de- creased in vitro and in vivo growth. Mol Carcinog. 2017; 56: 1182 1188. doi: $10.1002 / \mathrm{mc} .22550$

14. Gupta P. A review: Epidemiology, pathogenesis and prospect in developing vaccines for novel Coronavirus (COVID-19). Indian Journal of Tuberculosis. 2021; 68: 92-98. doi: 10.1016/j. ijtb.2020.09.021

15. Li H, Wang Y, Xu J, Cao B. Potential antiviral therapeutics for 2019 Novel Coronavirus. Zhonghua Jie He He Hu Xi Za Zhi. 2020; 43: E002. doi: 10.3760/cma. j.issn.1001-0939.2020.0002

16. Wang N, Shang J, Jiang S, Du L. Subunit vaccines against emerging pathogenic human coronavirus. Front Microbiol. 2020; 11: 298. doi: 10.3389 / fmicb. 2020.00298

17. Munjal A, Khandia R, Dhama K, Sachan S, Karthik K, Tiwari $\mathrm{R}$. et al. Advances in developing therapies to combat Zika virus: Current knowledge and future perspectives. Front Immunol. 2017; 8: 1469. doi: 10.3389 / fmicb.2017.01469

18. Singh RK, Dhama K, Chakraborty S, Tiwari R, Natesan S, Khandia R, et al. Nipah virus: Epidemiology, pathology, immunobiology and advances in diagnosis, vaccine designing and control strategies-a comprehensive review. Veterinary Quaterly. 2019; 39(1): 26-55. doi: 10.1080/01652176.2019.1580827

19. Dhama K, Karthik K, Khandia R, Chakraborty S, Munjal A, Latheef SK, et al. Advances in designing and developing vaccines, drugs, and therapies to counter Ebola virus. Front Immunol. 2018; 9: 1803. doi: 10.3389 / fimmu.2018.01803

20. Graham RL, Donaldson EF, Baric RS. A decade after SARS: Strategies for controlling emerging coronaviruses. Nat Rev Microbiol. 2013; 11(12): 836-848.

21. World Health Organization (WHO). Draft landscape of COVID-19 candidate vaccines. Website. https://www.who.int/ publications $/ \mathrm{m} /$ item/draft-landscape-of-covid-19-candidate-vaccines. Accessed February 12, 2021.

22. Callaway E. The race for coronavirus vaccines: A graphical guide. Nature. 2020; 580: 576-577. doi: 10.1038/d41586-02001221-y

23. Lan J, Ge J, Yu J, Shan S, Zhou H, Fan S, et al. Structure of the SARS-CoV-2 spike receptor-binding domain bound to the ACE2 receptor. Nature. 2020; 581(7807): 215-220. doi: 10.1038/s41586020-2180-5

24. Li F, Li W, Farzan M, Harrison SC. Structural biology: Structure of SARS coronavirus spike receptor-binding domain complexed with receptor. Science. 2005; 309(5742): 1864-1868. doi: 10.1126/ science. 1116480

25. Weingartl H, Czub M, Czub S, Neufeld J, Marszal P, Gren J, et al. Immunization with modified vaccinia virus Ankara-based recombinant vaccine against severe acute respiratory syndrome is 
associated with enhanced hepatitis in ferrets. $J$ Virol. 2004; 78(22): 12672-12676. doi: 10.1128/JVI.78.22.12672-12676.2004

26. Wang C, Li W, Drabek D, Okba NMA, Van Haperen R, Osterhaus ADME, et al. A human monoclonal antibody blocking SARS-CoV-2 infection. Nat Commun. 2020; 11: 2251. doi: 10.1038/ s41467-020-16256-y

27. Ozkan K. How close are we to a Covid-19 vaccine. Journal of Pure and Applied Microbiology. 2020; 14: 893-902. doi: 10.22207/ JPAM.14.SPL1.26

28. Shang W, Yang Y, Rao Y, Rao X. The outbreak of SARS-CoV-2 pneumonia calls for viral vaccines. NPJ Vaccines. 2020; 5: 18. doi: 10.1038/s41541-020-0170-0

29. Khatri K, Goyal AK, Gupta PN, Mishra N, Vyas SP. Plasmid DNA loaded chitosan nanoparticles for nasal mucosal immunization against hepatitis B. Int J Pharm. 2008; 354(1-2): 235-241. doi: 10.1016/j.ijpharm.2007.11.027

30. Lee J, Kumar SA, Jhan YY, Bishop CJ. Engineering DNA vaccines against infectious diseases. Acta Biomater. 2018; 80: 31-47. doi: 10.1016/j.actbio.2018.08.033

31. Lurie N, Saville M, Hatchett R, Halton J. Developing COVID-19 vaccines at pandemic speed. N Eng J Med. 2020; 382: 1969 1973.

32. Amanat F, Krammer F. SARS-CoV-2 vaccine: Status report. Immunity. 2020; 52: 583-589. doi: 10.1016/j.immuni.2020.03.007

33. Kalams SA, Parker SD, Elizaga M, Metch B, Edupuganti S, Hural J, et al. Safety and comparative immunogenicity of an HIV-1 DNA vaccine in combination with plasmid interleukin 12 and impact of intramuscular electroporation for delivery. J Infect Dis. 2013; 208(5); 818-829. doi: 10.1093/infdis/jit236

34. Muthumani K, Falzarano D, Reuschel EL, Tingey C, Flingai S, Villarreal DO, et al. A synthetic consensus anti-spike protein DNA vaccine induces protective immunity against Middle East respiratory syndrome coronavirus in nonhuman primates. Sci Transl Med. 2015; 19(7): 301 ra132. doi: 10.1126/ scitranslmed.aac7462

35. Porter KR, Ewing D, Chen L, Wu SJ, Hayes CG, Ferrari M, et al. Immunogenicity and protective efficacy of a vaxfectin-adjuvanted tetravalent dengue DNA vaccine. Vaccine. 2012; 30: 336341. doi: 10.1016/j.vaccine.2011.10.085

36. Mallilankaraman K, Shedlock DJ, Bao H, Kawalekar OU, Fagone $\mathrm{P}$, Ramanathan AA, et al. A DNA vaccine against chikungunya virus is protective in mice and induces neutralizing antibodies in mice and nonhuman primates. PLoS Neglected Tropical Diseases. 2011; 5: e928. doi: 10.1371/journal. pntd.0000928

37. Mahase E. Covid-19: what do we know so far about a vaccine? BMJ. 2020; 369: m1679. doi: 10.1136/bmj.m1679
38. Schlake T, Thess A, Fotin-Mleczek M, Kallen KJ. Developing mRNA-vaccine technologies. RNA Biology. 2012; 9: 1319-1330. doi: $10.4161 /$ rna.22269

39. Pardi N, Hogan MJ, Porter FW, Weissman D. mRNA vaccines - a new era in vaccinology. Nat Rev Drug Discov. 2018; 17: 261-279. doi: $10.1038 / \mathrm{nrd} .2017 .243$

40. Du L, Zhao G, Chan CCS, Sun S, Chen M, Liu Z. et al. Recombinant receptor- binding domain of SARS-CoV spike protein expressed in mammalian, insect and E. coli cells elicits potent neutralizing antibody and protective immunity. Virology. 2009; 393: 144-150. doi: 10.1016/j.virol.2009.07.018

41. Oscherwitz J. The promise and challenge of epitope focused vaccines. Hum Vaccin Immunother. 2016; 12: 2113-2116. doi: 10.1080/21645515.2016.1160977

42. Bachmann MF, Jennings GT. Vaccine delivery: A matter of size, geometry, kinetics and molecular patterns. Nat Rev Immunol. 2010; 10: 787-796. doi: 10.1038/nri2868

43. Caivano A, Doria-Rose NA, Buelow B, Sartorius R, Trovato M, D'Apice L, et al. HIV-1 Gag p17 presented as virus-like particles on the E2 scaffold from Geobacillusstearothermophilus induces sustained humoral and cellular immune responses in the absence of IFNg production by CD4 ${ }^{+}$T cells. Virology. 2010; 407: 296-305. doi: 10.1016/j.virol.2010.08.026

44. Zhang J, Zeng H, Gu J, Li H, Zheng L, Zou Q. Progress and Prospects on Vaccine Development against SARS-CoV-2. Vaccines. 2020; 8: 153. doi: 10.3390/vaccines 8020153

45. Jimenez-Guardeno JM, Regla-Nava JA, Nieto-Torres JL, DeDiego ML, Castano-Rodriguez C, Fernandez-Delgado R, et al. Identification of the mechanisms causing reversion to virulence in an attenuated SARS- CoV for the design of a genetically stable vaccine. PLoS Pathogen. 2015; 11: e1005215. doi: 10.1371/journal. ppat. 1005215

46. Plotkin S. History of vaccination. Proc Natl Acad Sci U S A. 2014; 111: 12283-12287. doi: 10.1073/pnas.1400472111

47. Almazan F, DeDiego ML, Sola I, Zuniga S, Nieto-Torres JL, Marquez-Jurado S. Engineering a replication- competent, propagation- defective middle east respiratory syndrome coronavirus as a vaccine candidate. mBio. 2013; 4(5): e00650-13. doi: 10.1128/ mBio.00650-13

48. Hou Y, Meulia T, Gao X, Saif LJ, Wang Q. Deletion of both the tyrosine- based endocytosis signal and the endoplasmic reticulum retrieval signal in the cytoplasmic tail of spike protein attenuates porcine epidemic diarrhea virus in pigs. J Virol. 2018; 93: e0175818. doi: 10.1128/JVI.01758-18

49. Cheng BYH, Ortiz- Riano E, Nogales A, de la Torre JC, Martínez-Sobrido L. Development of live- attenuated arenavirus vaccines based on codon deoptimization of the viral glycoprotein. $J$ 
Virol. 2015; 89: 3523-3533. doi: 10.1016/j.virol.2016.11.001

50. Mueller S, Stauft CB, Kalkeri R, Koidei F, Kushnir A, Tasker $\mathrm{S}$, et al. A codon- pair deoptimized live attenuated vaccine against respiratory syncytial virus is immunogenic and efficacious in nonhuman primates. Vacine. 2020; 38: 2943-2948. doi: 10.1016/j.vaccine.2020.02.056

51. Bolles M, Deming D, Long K, Agnihothram S, Whitmore A, Ferris $M$, et al. A double inactivated severe acute respiratory syndrome coronavirus vaccine provides incomplete protection in mice and induces increased eosinophilic proinflammatory pulmonary response upon challenge. J Virol. 2011; 85: 12201-12215. doi: 10.1128/JVI.06048-11

52. Lauring AS, Jones JO, Andino R. Rationalizing the development of live attenuated virus vaccines. Nat Biotechnol. 2010; 28: 573-579. doi: $10.1038 /$ nbt.1635

53. Gao Q, Bao L, Mao H, Wang L, Xu K, Yang M, et al. Development of an inactivated vaccine candidate for SARS-CoV-2. Science. 2020; 369: 77-81. doi: 10.1126/science.abc1932

54. Clinical trials.gov. Website. https://clinicaltrials.gov/ct2/ show $/$ NCT04456595? term $=$ vaccine $\&$ cond $=$ covid $-19 \& d r a w=2$. Accessed May 4, 2021.

55. Draper SJ, Heeney JL. Viruses as vaccine vectors for infectious diseases and cancer. Nat Rev Microbiol. 2010; 8: 62-73. doi: 10.1038/ nrmicro2240
56. Humphreys IR, Sebastian S. Novel viral vectors in infectious diseases. Immunology. 2018; 153: 1-9. doi: 10.1111/imm.12829

57. Ewer KJ, Lambe T, Rollier CS, Spencer AJ, Hill AV, Dorrell L. Viral vectors as vaccine platforms: From immunogenicity to impact. Curr Opin Immunol. 2016; 41: 47-54. doi: 10.1016/j. coi.2016.05.014

58. Zhu FC, Li YH, Guan XH, Hou LH, Wang WJ, Li JX, et al. Safety, tolerability, and immunogenicity of a recombinant adenovirus type- 5 vectored COVID-19 vaccine: A dose- escalation, openlabel, non- randomised, first- in-human trial. Lancet. 2020; 395 : 1845-1854. doi: 10.1016/S0140-6736(20)31208-3

59. Folegatti PM, Ewer KJ, Aley PK, Angus B, Becker S, Rammerstorfer SB, et al. Safety and immunogenicity of the ChAdOx1 $\mathrm{nCoV}-19$ vaccine against SARS- CoV-2: A preliminary report of a phase 1/2, single- blind, randomised controlled trial. Lancet. 2020; 396(10249): 467-478. doi: 10.1016/S0140-6736(20)31604-4

60. Iwasaki A, Yang Y. The potential danger of suboptimal antibody responses in COVID-19. Nat Rev Immunol. 2020; 20: 339-341. doi: 10.1038/s41577-020-0321-6

61. Tseng CT, Sbrana E, Iwata-Yoshikawa N, Newman PC, Garron T, Atmar RL. Immunization with SARS coronavirus vaccines leads to pulmonary immunopathology on challenge with the SARS virus. PLoS One. 2012; 7: e35421. doi: 10.1371/journal.pone.0035421 